\title{
Fintech and the Future of the Payment Landscape: The Mobile Wallet Ecosystem - A Challenge for Retail Banks?
}

\author{
Anna Eugenia Omarini ${ }^{1} \& 2$ \\ ${ }^{1}$ Tenured Researcher and Course Directos of Bank and Fintech, Department of Finance, Bocconi University, Milan, \\ Italy \\ ${ }^{2}$ SDA Bocconi School of Management, Milan, Italy \\ Correspondence: Anna Eugenia Omarini, Department of Finance, Bocconi University, Via Roentgen 1, 20136 Milan, \\ Italy. Tel: 39-02-5836-5958.
}

Received: September 7, 2018

Accepted: October 3, $2018 \quad$ Online Published: October 11, 2018

doi:10.5430/ijfr.v9n4p97

URL: https://doi.org/10.5430/ijfr.v9n4p97

\begin{abstract}
Technological innovation, recent regulatory initiatives and mass consumers' changing expectations are quickly re-shaping the payments' sector, paving the way to a more open environment where even non-banking players see a huge opportunity to gain momentum and disrupt the incumbents, namely the financial institutions. Fintech startups, high-tech firms but also mobile network operators are indeed challenging the status quo with their innovative propositions, trying to disintermediate banks from their traditional function of payment service providers. In the payments market, mobile wallets represent one of the innovations with highest potential of growth in the consumer-to-business segment. Payment market is a large and profitable segment for retail banking. Besides revenue streams from card payment transactions, new sources of revenueas and value creation have been unleashed by digital payments. This paper contributes to provide a better understanding of the mobile wallet ecosystem, also analyzing a set of four business cases so to identify potential sources of competitive advantage for retail banks in a market characterized by an increased non-bank competition. Mobile wallet platforms can be a powerful tool for banks to cope with the customer-centric approach. The structure of the paper analyse the recent trends in the financial services industry, involving the entry of new players (Fintech); the evolution of payments in the market; the concept of ecosystem applied to the new payment landscape; and it outlines the banks' roles in the new mobile payment environment.
\end{abstract}

Keywords: payments, fintech, mobile wallet, retail bank, platform, platform, ecosystem

JEL: G20, G21, G28

\section{Introduction}

A number of factors, including technological innovation, changing regulatory framework and consumers' expectations as well as increasing competition, have been deeply affecting the financial services industry in the recent years. In this fast-paced environment, financial institutions have seen their market leadership in many of their core businesses under attack from newcomers. One of the areas affected by radical change is payment, with non-bank innovators revolutionizing the way people make and receive (instant) payments for products and services. In recent years, the payment market has characterized by the rapid proliferation and widespread adoption of innovations. This fall into a number of avenues of change - from streamlining payments or integrating billing, to mobile payments, security developments, or cryptocurrencies and peer-to-peer transfers. Such innovations continue to make payments increasingly cashless and invisible, while enabling data-driven engagement platforms for customers. What is even more, is that payments started to be part of a much broader environment that includes other business areas, namely the mobile platform industry and non-payment value-added services market. Competition and, more in general, the complexity of the whole payments landscape is significantly increasing also with new entrants from different industries, willing to reach the mass market and being supported by cutting-edge technological infrastructures. To analyse the payment market, it is worth using an ecosystem view that considers payment services as part of a holistic and broader value proposition and strategy pursued by payments service providers. In light of that, a central role is that of mobile wallets, which incorporate mobile payments options and an array of additional services aimed at boosting the overall user experience. Indeed, particular attention is given to the mobile wallet 
ecosystem. Although even corporate payments and peer-to-peer payments are going through a significant transformation phase, payments in the retail space - consumer to business $(\mathrm{C} 2 \mathrm{~B})$ - will represent the focal research area of this paper. This choice is based on the widely recognized role of final user-consumer in the evolution of mobile payments, as well as on the fact that retail payments are of extremely important for banks to deliver and develop. At present, consumers are looking for a wider experience than just the payment itself: customer-engagement turns out to be the key to boost adoption and customer lock-in/retention. To achieve that, it is quite clear that the payment solutions can be part of a deeper strategy, aiming to improve the customer user experience through the offering of a more integrated value proposition. This paper contributes to provide a better understanding of the mobile wallet environment and to identify potential sources of competitive advantage for financial institutions in an environment characterized by an increasing non-bank competition.

The research question focuses on two main areas of analysis:

1. The dynamics of payments towards a mobile environment that led to the creation of a complex ecosystem, with new actors and relationships among stakeholders. In this part, the objective of the analysis is to understand the structure, the identify, and the nature of the relationships within the ecosystem, also identifying the main control points that represent the key for stakeholders to play a fundamental role in a given ecosystem.

2. The actions that retail banks can undertake from a strategic perspective to maintain their leadership in the payment industry and take advantage of new opportunities for value creation. In this part, the objective is to analyze a range of different strategic options to enable banks entering the mobile wallet market successfully.

The paper is structured into the following paragraphs: paragraph 2 will focus on the recent trends in the financial services industry, involving the entry of new players, namely Fintechs; paragraph 3 (and related) will discuss the evolution of payments in the market and then move into the mobile payments environment so to develop the framework of a mobile wallet. Paragraph 4 describes the rationale behind an ecosystem, which is central to analyse the new payment landscape. Paragraph 5 (and related) will provide an analysis of banks' roles in the mobile payment ecosystem at present. Paragraph 6 (and related) will describe why and how banks should develop their own strategy on the mobile wallet ecosystem and look for new business opportunities. In particular, sub-paragraph 6.2 outlines four interesting business cases. In paragraph 7, main conclusions and managerial implications are outlined for banks undertaking the mobile wallet business.

\section{Fintech and Digital Disruption in Financial Services}

In recent years, new trends have been changing the financial landscape. The word 'Fintech' (contraction for Financial Technology), introduced in 2006, reached quickly popularity in this context. Fintechs generally target specific segments of financial institutions value chain, aiming at providing services and solutions to loosen the bond between banks and their clients (Kotarba, 2016). According to Arner, Barberis \& Buckley (2015) the label Fintech entered the market as the employment of technology to provide financial services. Blake \& Vanham (2016) refer to Fintech as the use of technology with respect to the design and provision of financial services. According to Murad (2015) Fintechs can be a kind of "nimble piranhas, each focusing on a small part of a bank's business model to attack" In addition, $\mathrm{PwC}$ (2016a, p. 1) describes the word "Fintech" as the evolving intersection of financial services and technology. In the past, the term used to indicate the technology embedded in the backbone of financial institutions; however, now it encompasses any innovation in the financial services industry.

A broader definition of Fintech comes from the Financial Stability Board (FSI, 2017, June 27), which describes Fintech as follows: technologically enabled financial innovation that could result in new business models, applications, processes, or products with an associated material effect on financial markets and institutions and the provision of financial services.

The Fintech notion relates to disrupting start-ups (Chishti \& Barberis, 2016a), and they can have some or all of the following charactheristics (Drummer et al., 2016; Statista.com, 2017; Ferrari, 2016):

$>$ High degree of technology and innovation as source of competitive advantage. Technology is the key enabler to provide increased speed services, higher level of automation and security, and interoperability of services.

$>$ Agile business model - entrepreneurial spirit, flat organizational structure, faster internal processes, lower regulation constraints.

$>$ Unconventional marketing channels - mobile and internet space.

$>$ Customer-centric approach - improvement of customer experience through value added services and convenience in terms of money and time. 
The Fintech phenomenon is quickly growing within high-tech ecosystems such as Silicon Valley but also around the world; the annual funding of Fintech is growing up, and payments and lending markets are the primary areas of investment.

FinTech Report (2017) from Statista.com estimates that the total worldwide Fintech transaction value, $\$ 3,448$ billion in 2017, will more than double by 2022 reaching almost $\$ 8,000$ billion at a CAGR of 18 per cent. It is remarkable that digital payments contributed 80 per cent of the transaction value in 2017. Across regions, such as China and the United States, payments are expected to have a leading role in the Fintech growth. These numbers provide a view of the increasing impact and weight of Fintech in the financial services industry. Their growth is expected to continue and in the next years, Fintechs may become increasingly central, shaping the direction and pace of innovation across the industry.

\section{Evolution of the Payments Industry}

The payments industry has been going through significant innovations and changes over the last decades. The transformation process in payments can be outlined into five main phases characterized by a set of innovations. They are:

- Years 50's. First credit cards entered the market; and that is recognized to be the birth of electronic (and cashless) payments.

- Years 60's. Introduction of Automated Teller Machine (ATM) in UK by Barclays Bank. This is the birth of a global banking infrastructure with increasingly important role of electronics. The ATM was a revolutionary technology application to the financial sector, enabling important economic savings to financial institutions by introducing automation rather than human labor interacting with customers (Nicoletti, 2014; 2017).

Years 70's. Development of electronic trading (stock, foreign exchange) and the foundation of the Society for Worldwide International Financial Telecommunication (SWIFT), which was created to standardize and automate the international financial transactions.

- Years 80's. Mainframe evolution and computerization of financial industry bring increased speed and precision in data elaboration and information flow transmission, and then the birth of online and home banking (1983) from many of the major banks around the world (Citibank, Chase Bank, Chemical Bank, Barclays, Santander, etc.).

Years 90's. Internet Banking became widespread thanks to Internet services diffusion in developed countries. In 1996 Next Card is the first online credit provider; it is a financial system independent from banks, which came out.

\subsection{The Rise of Mobile Payments}

In this paragraph, the focus will be primarily on mobile payment transactions that occur between end-consumers and merchants/retailers, excluding inter-company transactions. Mobile Payments are considered the latest evolution in the field of electronic payments and the biggest opportunity in the mobile payment industry, with high growth potential (McKinsey \& Company, 2017). A mobile payment is defined as "any payment where a mobile device (phone and tablet) is used to initiate, authorize and confirm an exchange of financial value in return for goods and services." (Au \& Kauffman, 2008; Turowski and Pousttchi, 2013).

Given that, mobile payments rely on non-cash payment methods, which are cards, bank transfers, direct debits, and checks. Although there are still significant geographical discrepancies, data on cashless payments show a solid double-digit growth, implying a gradual shift towards a cashless society in some geographical areas, such as China and Northern Europe. All this provides a solid ground for further innovation, such as mobile payments (Bose \& Denis, 2017). Acceptance by users is indeed a central topic for mobile payments diffusion due to a number of reasons (e.g. perceived security, perceived convenience, etc.) and, thus, growth of cashless payments market shows that the general public is getting ready for new innovative solutions after cash payments dominated the economy for centuries.

The combination between mobile services and cashless card-based payments has led to the rise of mobile payments. Indeed, mobile payments market is quickly growing and the transactions value is expected to exceed $\$ 1,000$ billion in 2019, with over 1 billion users in 2019 from only 60 million in 2015 (Deutsche Bank AG, 2016; Bose \& Denis, 2017).

Given that, it is useful to segment the mobile payments into different categories of services according the purpose of use and the device through which the transaction is made. Based on the purpose of use, mobile payments can be classified as follows: 
- Mobile Remote Payment. This is a service that enables to pay a good or service and it is performed independently by the mobile phone's location. E-commerce or m-commerce transactions are examples of that.

- Mobile Proximity Payment. It allows making in-store (proximity) payments, so that the buyer makes the payment to the merchant via customer's smartphone, so to replace contactless cards.

- $\quad$ Mobile P2P (Person to Person) and Mobile P2B (Person to Business). They both allow making money transfers directly from either users' bank account or a prepaid in-app account between two users (P2P) and/or between merchants and customers.

\subsubsection{Main Factors Behind Mobile Payments Development and Adoption}

According to Deloitte (2015) there are three main disruptive factors, which are highly interrelated, that have helped developing this market, and they are:

a) Technology-enabled innovations.

b) Regulatory intervention.

c) Shift in consumers' preferences.

a) Technology-enabled innovations. In this category of factors the main innovations are the following:

- Smartphone and broadband diffusion drive the mobile revolution. The first enabler at the basis of the mobile development is the widespread of mobile devices with smartphones having clearly the key role. There are 1.5 billion smartphones sold in 2016 and this number is expected to reach almost 3 billion in 2020 (Statista.com, 2016). Smartphones offer the possibility to use mobile internet at a fixed and low cost as well as with increasingly high internet speed. Fostering access to cloud-based technologies and with broadband allowing fast wide bandwidth data transmission, which transports multiple signals and traffic types, smartphones enable any individual to get access to digital services anywhere and anytime.

- Near-Field-Communication (NFC) technology. This is a key feature that enables consumers to use their smartphones to make in-store purchases. As mentioned, in-store (proximity) payments represent likely the fastest-growing phenomenon in the payment industry and NFC is a key facilitator of their increasing adoption rate (Bose \& Denis, 2017). NFC is a communication protocol that enables contactless payments by establishing wireless communication between two technical devices, for instance between a mobile phone and a point of sales (POS) terminal, by tapping the mobile device in proximity of the POS terminal (Pham \& Ho, 2015). The major advantages of NFC technology (Grassie, 2007) are the following ones: 1) scope and availability. It can be implemented in all existing mobile terminals (on the condition of the installation of a chip) generating a wide range of new services for users and the terminal itself; 2) wide array of applications (paying bills, car payments, leisure, etc.); 3) easiness of use. It is only needed that the parties involved stay within a specific proximity (up to 20cm); 4) the generation of value-added services; and finally; 5) security, as it requires that users manually activate or approach the receiver for payment. Transaction security is guaranteed through a process called tokenization that translates consumer credit card details into temporary "tokens", allowing payments to be authorized without the need to disclose credit card details to the retailer (Broom, 2015). Tokenization converts card details into a token, that consists of a string of random numbers and letters, which changes every time a transaction takes place, so that customer's card details are never shown (Hoffman, 2017).

Open Application Programming Interfaces (API). They are a set of tools that allow different software components or systems to communicate with one another effectively (Chishti \& Barberis, 2016b). APIs facilitates the interaction between two or more online connected services, providing the opportunity to build solutions that integrate and combine different services and data through standardized interfaces across all stakeholders. Open APIs are indeed used for banking, payments, and add-on services. They can help banks to expand their business, add new services, and open new channels. By using APIs, banks can incorporate the technology from Fintech firms into the key areas in which support is required - simplifying the process of adding innovative technology services by piecing together building blocks of flexible services, rather than building the technology from scratch. Open APIs are considered as a key factor for the future development of banking and payment systems, providing benefits for all the stakeholders involved.

b) Regulatory Intervention is also driving the change in the payments industry concistently. In recent years, the Key Regulations and Industry Initiatives (KRIIs) have been taking globally a transformative role, actively stimulating competition among payment service providers and disrupt inertia in various segments of the payments'value chain (Bose \& Denis, 2017). The main results, that regulators expect to achieve, are broad - risk reduction, standardization, 
competition, transparency and innovation - and based on a short-medium timeframe (2017-2020).

European Union is making significant efforts to increase payment process standardization and harmonization. Initiatives such as the Single European Payment Area (SEPA) and ISO 20022 are the main examples. SEPA was introduced in the EU regions by the European Payment Council (EPC), in collaboration with Member States to harmonize electronic payments in the European Union. SEPA provides rulebooks and guidelines for each of the electronic payment instrument to standardize payments processing across EU (European Payments Council, 2018); ISO 20022 established a standard with many real-time payment systems utilizing it. Nevertheless, there are still challenges with respect to regional differences that need to be addressed so to achieve a full harmonization (ISO20022.org, 2018). The direction is however clear. The regulator aims at eroding barriers to entry for newcomers, by providing standardized and fair field for all the competitors including non-banking entities.

This mainstream idea entered the first time into the European Union with the arrival of the Payment Service Directive (Directive 2007/64/EC, known as PSD 1), which paved the way to the creation of a single, innovative European market with a fully interoperable legal framework (Ley, Foottit, \& Honig, 2015). It aimed at bringing market efficiency, consumer protection, competition, choice, and security. Then this Directive was revised with a second one (Directive 2015/2366/EU, known as PSD2), which can be considered the most disruptive initiative. PSD2 keeps pursuing the same objectives as PSD1 but it is going further. It entered in the market on January $13^{\text {th }}$, 2016 and Member States have had until January $12^{\text {th }}, 2018$ to translate it into national laws. Regulators expected the PSD2 to create a level playing field for all stakeholders, opening the payments' market to new entrants in Europe and, consequently, increasing market efficiency and security through increased competition. (Bose \& Denis, 2017). PSD2 addresses many issues that emerged from PSD1, the most significant of which is the regulation of third-party payments providers (TPPs). This initiative allows access to customer account information from third parties that are appropriately licensed, and that have received explicit customer consent and prohibits that banks treat payments via third parties differently, for instance by charging higher fees to merchants and consumers. The access for third parties to customer account information is provided through open APIs (Ley, Foottit, \& Honig, 2015). PSD2 is expected to boost innovation in business models and banking services and will be an important step towards open banking in Europe. On the other side of the coin, this might generate a potential loss of control by banks of the customers' interfaces, which might undermine banks' position over customer relationship management and decreasing the role of banks in being central to customers' everyday lives.

Regulations have lowered barriers to entry in the mobile payments market. So that high-tech companies such as Google, Apple and Samsung as well as Fintechs (e.g. Paypal and Venmo) entered the market and gained momentum, managing to increase their market share over the last years. Their value proposition is based on high technological capabilities and customer-centric focus, which are threatening the traditional retail banks predominance in the payments industry. The competitive advantages of non-bank players relate to the technology they have developed to harness and process data, while providing a superior customer experience.

c) Shift in Consumers' preferences. The diffusion of Internet on large scale, even on mobile devices (e.g. smartphones, tablets etc.) has shifted the customer experience towards new paradigms. Indeed, from a pure content/service user people have become a 'value creator' with a multitude of different options to choose among them. The market indeed presents some specific characteristics that have been paving the way for new challenges for incumbents and chance of entry for newcomers. Customers are now looking for services with innovative and seamless features (Deutsche Bank AG, 2016) such as:

- Efficient and real-time. Process need to be streamlined and fast. For instance, ordering a service should occur simultaneously with accepting the invoice and authorizing the payment.

- Integrated and flexible. Customers expect one single portal, allowing reconciliation across different user profiles.

- Accessible and user-friendly. Users want to use services from multiple devices and - channel convergence - in a single easy-to-use platform.

- Tailored and personalized. With big data analytics, at present, it is possible shaping sophisticated user profiles.

- Intuitive. Artificial intelligence enhancements will shortly enable to anticipate user needs, paving the way for new opportunities for breakthrough innovation.

Young people, the so-called millennials, do not yet have deep relationships with banks, and some do not see banks as a necessity. Millennials prefer alternative financial products such as prepaid cards to bank accounts with traditional banks (Waupsh, 2017). In summary, as consumers get used to the benefits of using technology in their daily lives, their expectations are growing and customers are becoming more demanding. Non-bank digital entrants have used 
superior design and user interface to build solutions that often surpass consumers' and merchants' expectations in terms of end-to-end customer experience. By integrating payments into commerce, non-bank attackers have created more seamless, personalized and interactive experiences (McKinsey \& Company, 2015).

\subsection{Mobile Wallets}

Mobile wallets are tools that incorporate mobile remote payments, mobile proximity payments as well as other value-added services such as mobile loyalty, ticketing, private ID, etc. A mobile wallet is the interface platform that allows consumers to use the mentioned mobile services, replacing the "material" wallet. A mobile wallet, also called a digital wallet, is a service that allows users to access electronic funds in their smartphones and pay for goods and services with these funds. By allowing users to store their credit card, debit card, gift card, or bank account data in their phones, wallet apps eliminate the need to carry around multiple physical cards. Consumers can also store and organize coupons, loyalty programs, payment cards, tickets, car insurance identification, and anything else that can be turned into a digital item from its original paper or plastic form (Parker, 2014; Tabakovic \& Sylvest Olsen, Mobile Wallet: Strategic Options for Banks, 2013).

The most interesting feature is that the payment service is 'just' an underlying facilitator, whereas the driving forces of the mobile wallet are the mobile marketing services connected to the mobile wallet (Tabakovic \& Sylvest Olsen, Mobile Wallet: Strategic Options for Banks, 2013). Worldwide, the estimated total value of mobile wallet transactions is around $\$ 75$ billion in 2016 with a CAGR of 30 per cent from 2013. In a survey by Edgar, Dunn \& Company (2017), 60 per cent of respondents, categorized as payment experts, believe that mobile wallets will evolve to become the primary payment instruments for consumers.

A mobile wallet can contain, generate, and enable a wide array of non-payments services, the so called value-added services (VASs). Table 1 provides an overview of the main services a mobile wallet is able to deliver.

Table 1. Range of services of mobile wallets

Mobile Wallet Opportunity (Mobeyforum.com, 2013)

\begin{tabular}{|c|c|c|c|}
\hline $\begin{array}{l}\text { Financial or mobile } \\
\text { banking applications: }\end{array}$ & Mobile Payments: & Identity: & Mobile Commerce: \\
\hline $\begin{array}{l}\text { Account access / status / } \\
\text { balance information } \\
\text { Financial transaction options } \\
\text { (money send/transfer, bill } \\
\text { payment, cash-out, wealth } \\
\text { management, stock exchange } \\
\text { investments) } \\
\text { Storage of payments cards } \\
\text { from multiple issuers (Debit, } \\
\text { Credit, Pre-paid) }\end{array}$ & $\begin{array}{c}\text { Mobile } \\
\text { payments }\end{array}$ & $\begin{array}{l}\text { Digital identification } \\
\text { through mobile } \\
\text { device, with the } \\
\text { support of } \\
\text { governmental } \\
\text { organizations, telecom } \\
\text { operators or banks } \\
\text { Authentication or } \\
\text { Membership cards, boarding } \\
\text { passes, driver's licenses }\end{array}$ & $\begin{array}{l}\text { Coupons and offers } \\
\text { Loyalty cards } \\
\text { Tickets for transport or } \\
\text { entertainment } \\
\text { Mobile advertising } \\
\text { Location-based or } \\
\text { contextual services }\end{array}$ \\
\hline
\end{tabular}

If we move analyzing the mobile wallet structure, then there are two ways to classify it and they are:

- Vertical wallets. In this case, the wallet provider acts as exclusive service provider. It designs, controls, and manages the mobile wallet and provides services for it. For example, a financial institution develops its own mobile wallet and provides all its financial services in the wallet. This type of wallet maximizes the control and brand value of the service provider, and by this way is not threatened by competition in providing services into the wallet. On the other hand, the wallet operates in a 'closed ecosystem' (Guaus, 2013), and this may reduce its circularity.

- Horizontal wallets. The mobile wallet provider aims to offer a wallet capable of integrating services from other service providers. The wallet provider aggregates services and drives mass-market adoption. It may offer design and management services for other service providers. This structure of wallet maximizes the control and brand value of the wallet provider, giving the wallet provider a great visibility. It maximizes adoption due to the wide range of services offered from different providers. Most of the mobile wallets are horizontal wallets. It is also possible to combine the features of vertical and horizontal wallets to create a variety of hybrid wallets. The extent, to which the 
two approaches are combined, depends on the degree of openness and control the wallet provider wishes to retain over its solution. This option is described in terms of an 'open ecosystem' (Guaus, 2013). In this category of wallet a further classification can be done and it is that oultines two different types of wallets, integrated wallets and umbrella wallets, which are described briefly below.

- Umbrella walletIt is a mobile wallet designed to host other third party mobile wallets. The features defined at the top level are not particularly significant in this model and the focus is on managing priority and status of the different services and/or sub-wallets contained in the umbrella wallet (Guaus, 2013). Wallets within the umbrella wallet can get access via the umbrella wallet environment, or by directly bypassing the umbrella level entirely. Umbrella wallet is positioned as a 'vehicle of convenience', an enabler of other wallets, each of which has its own brand. (Debray, Kwon, \& Gill, 2014)

- Integrated wallet. It is a mobile wallet where the services, even if they are provided by external providers, are organized under the wallet provider's brand name. The wallet provider dictates which services can be offered inside its solution. A number of additional features are defined at the top level - such as how to browse the services. No third-party organizers (independent sub-wallets) are permitted to be included in the wallet environment (Debray, Kwon, \& Gill, 2014).

\section{The Mobile Wallet Ecosystem}

The mobile wallet phenomenon requires a number of different stakeholders and cross relationships, which are undertaking in the new payments landscape. At this stage of analysis, it is important to understand where banks should play their role to keep them central in their customers' everyday life. In order to do this, first, it is relevant to introduce the concept of 'platform', which is the core element of every modern ecosystem, creating relationships among their actors and shaping their internal and external dynamics (e.g. balance of power, equilibria).

Mobile wallets work as multi-sided platforms (MSP) (Kazan \& Damsgaard, 2013) and thus possess features quite different from previous innovations in the finance sector. A MSP is defined as "an organization that creates value primarily by enabling direct interactions between two (or more) distinct types of affiliated customers". It is clear that mobile wallets through their services enable interactions between consumers and merchants, involving payments of goods/services and other forms of interactions based on the wallet value added services that consumers can benefit from it. A multi-sided platform has the following characteristics (Staykova \& Damsgaard, 2015; Kazan \& Damsgaard, 2013):

- Direct interaction between different ecosystem stakeholders. It is the key criterion to categorize a platform as multi-sided. In the basic scenario for mobile wallets, the wallet app allows payers to use directly their payment card to pay merchants. It is important that there is a direct commercial relationship between the buyer and the seller as it is in this case.

- Network effects reflect the idea that the value of a platform correlates positively with the number of platform's users on all the sides of the platform. There is no value in a platform without users. When network effect is present, the value of a product or service increases as more people use it (Verona, 2015). In other words, digital platforms are able to create feedback loops between content producers and content users and platform providers should ensure that the right consumers are connecting with the right producers of contents (Bose \& Denis, 2017; Tewari, 2014). In the case of payments, it is clear that, as the number of users of mobile wallets increases, merchants have incentives to accept payments via mobile wallets. The equivalent applies if we take a customer's perspective: mobile payments have to be accepted by merchants; otherwise, the mobile wallet has no value at all for them.

- Homing Costs are expenses - adoption, operation, opportunity costs - arising when users are affiliated with a platform. These costs include all the investments/costs related to the existence of the platform, such as the fact that merchants should purchase NFC terminals to enable customers' payments.

- $\quad$ Switching Costs are the costs associated with switching to an alternative platform. In the case of payments, most merchants are tied to contractual commitments, which is a high barrier to abandon current terminals, while consumers may be forced to lose their in-wallet benefits (e.g. loyalty points, retail discounts, cashback) if they switch to another wallet application.

- Bundling and Envelopment refer to a form of offering where two or more single products or services are offered as a package (Shapiro \& Varian, 1999). Loyalty and other reward programs as well as mobile banking services bundled with $\mathrm{m}$-wallets are clear examples of that. 
- Platform Design is the interface design in terms of two dimensions. System development dimension: MSPs can be close or open systems according the degree of involvement of third parties. Closed systems exclude third parties from any platform modification, while open systems allow third parties to contribute to platform development. System usage dimension: systems differ with respect to the extent to which complementary software can integrate with the system. In the payments context, the distinction between vertical and horizontal wallet offers a view of this feature.

- Technological Solution (Customer Ownership and Hardware). Different platform designs bring different types of control on third party providers and on their complementary products, having implications on end users too. By controlling the customer relationship, platform providers can extract value (fees) and the level of control determines the extent of customer ownership. In addition, a controlled hardware infrastructure can serve as a further defense and layer of control, to protect value creation. Payments, especially at the checkout counter, are based on hardware infrastructure (e.g. payment cards and terminals). A Payment platform provider gets a strong effect on control, with the chance to exclude third parties and generate lock-in effects on users.

To sum up, the platform organization itself thereby acts as an intermediary, which can be managed by one or more entities (platform providers). The primary objective of a platform is to coordinate and facilitate the direct interactions in a controlled manner, providing the architecture and a set of rules for each participant (Eisenmann, Parker, \& van Alstyne, 2006). We have pointed out that mobile wallet applications possess all the key features of a multi-sided platform. MSPs are the key elements around which a number of stakeholders revolve, and create a real business ecosystem with a complex network of relationships among the various stakeholders. MSPs have brought a new concept of business model that revolves around the role of platforms.

\subsection{Mobile Wallets and a New Wave of Business Models}

With the dawn of Internet and the digital revolution, and the diffusion of mobile applications, digital platforms started widespreading and, with them, new business models have established. In the digital platforms context, the provision of new services through appropriate cooperation and coordination models (including revenue sharing models) becomes the central aspect for every business model (Methlie \& Pedersen, 2001; Lindmark et al, 2004). From then onwards, new business models started dealing with the blur of traditional firm boundaries. As a result, the focus of business modelling gradually shifted from the single firm to networks of firms, and from simple concepts of interaction or revenue generation to extensive concepts encompassing the value network, the functional architecture, the financial model, and the eventual value proposition made to the user (Linder \& Cantrell, 2000; Faber et al, 2003). This shift, from a single-firm revenue generation perspective towards a multi-firm control view, led to new business model concepts aiming to answer questions, which are not part of this paper, such as "Who controls the value network and the overall system design?" and "Is substantial value being produced by this model (or not)?" (Ballon, 2007). In other words, the platform approach is fundamentally different from traditional business models, where value is produced upstream and consumed downstream, where there are companies that create products or services, and sell them to customers. Instead, the platform gives the consumer the freedom to both create and consume value (Tewari, 2014). More in detail, platform business models may have some of the following peculiar features we can also find in a mobile wallet platform, such as:

- User acquisition is not as straightforward as in traditional business models. Platforms suffer from the chicken-egg problem, where both sides of the platforms (users and merchants) are not incentivized to join the platform network unless there is already high adoption on the other side of the platform.

- Product design and management focuses on the users' interaction - merchants and other service providers and consumers - with each other rather than on being attractive only for the final consumer (Tewari, 2014). The platform should indeed maximize value-creating interactions between users. The new ecosystem must have a robust governance structure that will set common rules and standards to develop networks and services with clear responsibility split in term of client and risk management. Standards have to be established, particularly for APIs. Such standards will ensure seamless collaboration between ecosystem participants (Bose \& Denis, 2017).

- Monetization for platforms business models needs to identify and remunerate value creators such as content providers as well as users. Indeed, in mobile wallet users get value from the use of the platform (e.g. discounts, coupons, etc.). In addition, platforms monetize the transactions occurring through the platform. The obvious case is card-based mobile payments in mobile wallets. Platform may also get revenue from 'consumer attention' through advertising as well as licensing technological infrastructure (open APIs) (Tewari, 2014). Monetization of API- based value-added services, for example, could be delivered in collaboration payments products and services. 
In an even more simplified way, a business ecosystem may be considered as "a collection of (many) firms engaged in joint production, whose choices and actions are interdependent" (Boudreau \& Hagiu, 2008) and in which "relationships underlying specific roles and overlapping hierarchies are formed to create mutual value for its stakeholders" ( Sareen \& Tewari, 2014).

Moore (1996) started reckoning that traditional models of management, based on competition in the provision of products and services as well as process improvement are no longer able to enable companies to survive in the modern and rapidly evolving business environment. Firms fail despite having good products and services propositions and well-established internal processes in place. Therefore, for a firm to prosper, it is essential to focus on its surrounding economic environment, including factors and firms influencing its evolution. The new paradigm requires taking a different perspective, seeing a single business as part of a wider economic ecosystem. Figure 1 illustrates the structure of a typical business ecosystem (Moore, 1996). We can notice that the boundaries of an ecosystem extend to a wide range of organizations and individuals far beyond the core business, which includes direct supply chain and distribution channel partners, and even a larger 'extended enterprise'. In business ecosystems, firms hold specific core capabilities that form the basis of value creation and are useful to produce core products to customers. Again, core products are surrounded by a number of complementary products and services, which improve the customer experience.

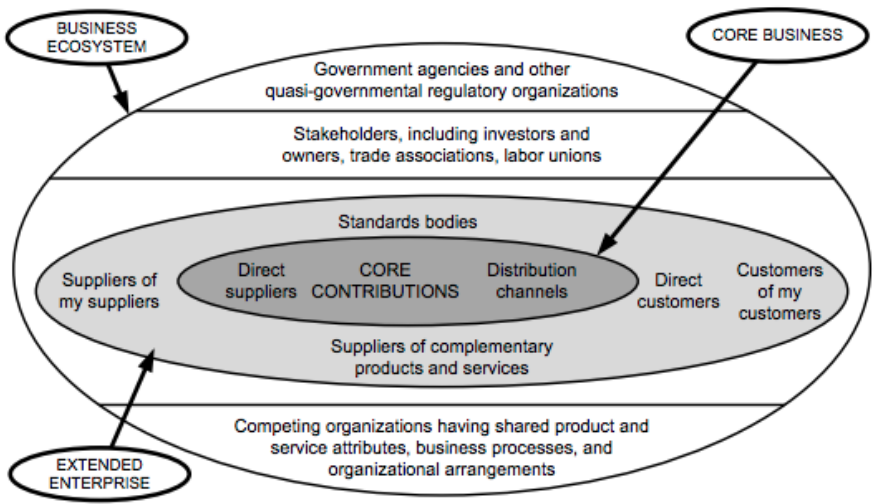

Figure 1. Moore's business ecosystem layers

The Death of Competition: Leadership and Strategy in the Age of Business Ecosystems (Moore, 1996)

Iansiti and Levien (2004) continued Moore's work and developed an approach that focuses on business networks, trying to understand how firms should manage the situation when they are part of an ecosystem. Firms rely on assets, which they do not own but have access to, through a business network, and they need to deal with that effectively (Iansiti \& Levien, 2004). Ecosystems are not homogeneous in structure. The majority of them have richly connected network hubs (or gatekeeping roles or control points) that shape the nature of the relationships between ecosystem's stakeholders and thus can have a profound impact on the overall health of the ecosystem based on the efficiency of their control. In fact, these hubs enhance stability, predictability, and other measures of system health by regulating connections and creating stable and predictable platforms on which other network members can rely. The control over a network hub is a key source of competitive advantage for ecosystem's stakeholders. Iansiti and Levien (2004) describe three classes of actors within the business ecosystem, competing to gain control over network hubs, but with different goals: keystones, dominators, and niche players. A keystone is considered the ecosystem leader, acting to improve the overall health of the ecosystem and, in doing so, benefits the sustained performance of the firm. To create value, it shares assets (e.g. platforms, operating systems, etc.) with its network by leveraging its central hub position in the network. A dominator, on the other hand, acts to integrate vertically or horizontally to directly control and own a large proportion of a network, capturing most of the value created by the network and leaving little opportunity for the emergence of a meaningful ecosystem. They pursue control of value extraction alone, with little new value to its network, leaving a 'starved and unstable' ecosystem around it. Niche players, finally, focus their efforts and resources on a specific domain of expertise by leveraging the complementary resources of a keystone or other niche players. The main difference with dominators is that, despite not controlling a central part of the ecosystem, they contribute to create value, by performing their specific set of activities. In conclusion, Iansiti and 
Levien (2004) in the 'Keystone Advantage' identify three critical success factors for a business ecosystem based on the efficiency of hubs control. First, productivity, which is the network's ability to convert technology and other factors of production into new products and lower costs. Return on invested capital (ROIC) is one of the most common measures for that. Second, robustness that describes the ecosystem capability of surviving in presence of internal or external shocks undermining the whole ecosystem structure. It means that the ecosystem is able to adapt itself to the changing external environment, just as animal species have to do within biological environments. Third, the ability to create niches and opportunities for new firms. Niche creation is important to extract value from diversity, which is a new and interesting source of business value.

\subsection{The Mobile Wallet Ecosystem Structure}

Mobile wallet ecosystem presents a high degree of complexity due to its peculiar characteristics. Indeed, it can be broken down into layers, which can be considered as sub-ecosystems, each one has its own forces and equilibria. To understand the big picture of a mobile wallet ecosystem and its internal dynamics we have synthetize the key features in Figure 2, which outlines the main layers (alias sub-ecosystems), their interactions and relationships.

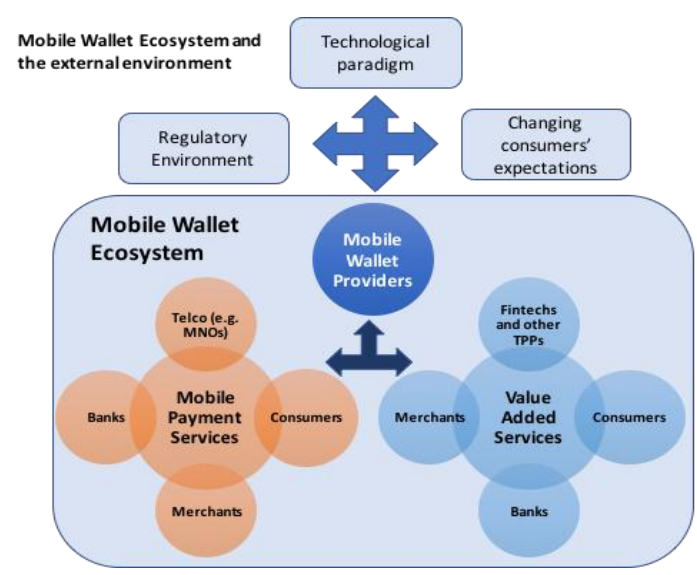

Figure 2. Mobile Wallet ecosystem as a combination of mobile payments and value-added services

The first sub-ecosystem is that of mobile wallet providers where behind it lies both the mobile industry as well as the card-based payment system. In the first one, there is a variety of stakeholders (such as Mobile Network Operators MNO-, Mobile device manufacturers, content providers, mobile operating system providers and users) and networks (Karvonen \& Warsta, 2004). Given that, it is useful to outline that different models (Tewari, 2014) can take place at this layer, such as the one where is the MNO plays the role of the keystone (e.g. Vodafone Live); or device manufacturers plays this role (e.g. Apple iPhone). In this case, the device manufacturer functions as a portal provider, choosing and controlling which services are available to consumers. Alternatively, it can be mentioned another option that is when content providers take the role of portal provider (e.g. Facebook mobile).

Moving on the second layers, it has to be outlined the card-based infrastructure, which makes the payments among the different counterparts. This layer is composed by many stakeholders, which are the following:

\section{- Merchants;}

- Consumers;

- Acquiring banks - merchant's financial institution responsible for the management of merchant's account, and the verification of the deposited payment instrument; issuing banks - client's financial institution managing the client's account and afford the electronic payment instruments to be used by clients (Téllez \& Sherali, 2017);

- Network scheme owners, which provide payment schemes, card schemes mainly, controlling the operation and clearing of card payments, passing card transaction details from the acquirer to the issuer and for passing payments back to the acquirer, which in turn pays the merchant.

In this space, there is a full collaboration among banks and network scheme providers in order to guarantee the acceptance and adoption of cards among merchants and customers. In this case, banks and network scheme owners 
are both keystones in the ecosystem. Given the previous layers, it is on them that the mobile payment ecosystem was born and is able to develop.

\section{Banks and the Mobile Payment Ecosystem (At Present)}

Given all that above, we move on the way banks are playing their role in this market, at present. On this purpose, there are three main models, which can be useful to explain banks' roles, and they are:

- Bank-centric model. It is when a bank deploys mobile payment applications or devices to customers and ensures merchants that have the required point-of-sale (POS) acceptance capability. The bank controls all the value chain, from payment processing, with the related revenue streams, to the user's data management and ownership. A bank establishes relationships with merchants and consumers, creating further value in terms of brand awareness, loyalty, etc. The bank plays the role of keystone, as its interest is to make sure the whole ecosystem can maximize its value creation, while merchants and users are always the dominators pursuing maximization of their value creation getting low cost and efficient services - regardless the status of the ecosystem. Furthermore, banks can reach this status by leveraging economies of scale and scope in the payment processing, having infrastructures and agreements in place to manage all the transactions and leveraging on the high volumes of daily transactions, that enable them to lower transaction costs.

- Operator-centric model. It is when the mobile operator acts independently to deploy mobile payment applications, in particular to NFC-enabled mobile devices. The applications may support a prepaid stored value model or charges may be integrated into the customer's wireless bill. In most cases, the mobile operator provides the customer with a NFC SIM card, which makes NFC transactions possible via merchant's POS terminal and facilitates the user's adoption and the diffusion of this model in the market. In this case, MNOs try to disintermediate banks from mobile payments and it is interesting to understand how they can achieve that. This is possible because they can count on the possibility to control the service brokerage hub easily, and providing users with mobile payment applications as part of their mobile subscription.

- Collaboration model. It is when there is collaboration among banks, mobile operators and other stakeholders in the mobile payments value chain, including a potential trusted third party that manages the deployment of mobile applications. Payments in this model are processed over the existing financial networks with credits and debits to the appropriate accounts. Potential sources of revenue include merchant commissions, merchant and consumer transaction fees, new customer acquisition fees, and marketing fees. Generally fees and commissions are split between banks, mobile operators, and perhaps third-party trusted service managers. Both banks and MNOs can be considered as keystones, being incentivized to make the ecosystem growing because they get and share revenues from each transaction. Equilibrium of the system is indeed fostered by this revenue sharing mechanism and by the synergies that collaboration generates from complementary core competences (e.g. payments experience and infrastructure for banks while NFC technology for MNOs).

- Device-centric model. It is when mobile payment services are offered by device manufacturers. The device would integrate a secure element to ensure transaction management and security as well as the payment interface directly installed on the mobile device. This model relies on a degree of collaboration with the payment network providers, which areencharge to manage the payment transactions. The control over the activities of charging and billing are facilitated by the possibility to get the first point of contact with consumers into their mobile devices, being able to control which applications can be included into their operating system.

\subsection{From Mobile Payments to Mobile Wallets}

Given all that above, the situation might become even more complex if we think of the rise of mobile wallets, which may embody more other roles, such as that of wallet provider and value-added services providers. They represent one of the most significant sources of value for mobile wallets, being the key sparkle to boost adoption and continuous usage of the wallets, because they are focused on the entire process of the customer experience (Tabakovic \& Sylvest Olsen, 2013; Tavilla, 2017). The first actor is the organization/brand that issues the mobile wallet functionality to the mobile wallet users, which represents the wallet interface with users. Gaining control over it, it is of primary importance and it is not surprising that so many actors aim to achieve this role and come up with their own wallet. Banks (e.g. JP Morgan Chase), Fintechs (e.g. PayPal), device manufacturers (e.g. Apple, Samsung), tech firms (e.g. Google, Amazon), retailers (e.g. Starbucks, Walmart) and network operators (e.g. Vodafone) are all keen to provide their own wallets.

M-wallet platform providers can get value from multiple revenue streams, including payment transaction fees as for bank-centric models of mobile payments, product, cross selling, licensing of open APIs to third-party service 
providers and big data-related services. Mobile wallet providers can leverage the strong opportunity to attract new customers and tighten their relationships with them as well as increase brand awareness, loyalty and customer retention (Tabakovic \& Sylvest Olsen, 2013). In an ecosystem perspective, wallet providers play the role of keystone, because their interest is to provide a healthy environment in which service providers (both payment and value-added services) can operate and collaborate. They are indeed able to extract the largest amount of value from the use of third party provider services and that is why there are incentives to guarantee a favorable environment for all the stakeholders.

In this ecosystem, they are examples of niche players. Most of them are Fintech, which create remarkable value for the whole ecosystem even though they focus only on specific services such as reward-based mechanisms for wallet users.

Banks and other payment institutions are already involved in mobile wallet ecosystems by playing a set of multiple roles: they can be acquirers, issuers in the payment process, but also wallet and contents providers. Notwithstanding they should consider it strategically, because they both manage customers' money; they are owner of payment infrastructures and services already in place. Indeed, people highly trust banks to manage personal financial operations and have well-established security processes and systems in place to do it safely. Banks already hold customers' financial accounts and are established issuers of payment cards and other payment instruments, allowing them to obtain economies of scale and scope. However, to take full advantage of these opportunities, banks need to cope with factors such as time-to-market, speed of execution, new security and authentication procedures, in order to gain a deep understanding of the mobile environment (Staykova \& Damsgaard, 2015; Tabakovic \& Sylvest Olsen, Mobile Wallet: Strategic Options for Banks, 2013).

\section{Why and How Should Retail Banks Take Mobile Wallet Ecosystem into Their Strategies?}

Payments market is a large and profitable segment for retail banking. Beside revenue streams from card payment transactions, new sources of revenue and value creation have been unleashed by digital payments. Digital payments could also help banks to explore new services to their clients, generating further revenue streams (Bose \& Denis, 2017).

For many years, payment services has been considered the Cinderella of banks' services, but once technology has started evolving they changed into a kind of a Trojan horse, which opens new opportunities of business to other competitors; increases stickness to customers, and deplates the role of banks in being central to their customers' everyday lives.

From the analysis undertaken so far, it is evident that banks, mobile device manufacturers and mobile network operators may effectively target the highest number of control points in the mobile wallet ecosystem. We could argue that they are likely the main candidates for taking on the role of keystones in the ecosystem, by acting as wallet platform providers. Given that, there are interesting examples in the market showing that some of these entities are currently coming up with the most successful mobile wallets such as Apple Pay, Vodafone Pay, Samsung Pay, and Chase Pay, just to mentione some of them. All of them are leveraging their broad customer base, technological expertise and specific position in the ecosystem to deliver value to users and gain control of the m-wallet business. A further conclusion we can draw from the above analysis has to do with the size of the ecosystem. In the case of mobile wallets, the value that the platform provider, which plays the ecosystem keystone role, can get from the ecosystem is correlated with the ecosystem size positively. Indeed, as the size of the ecosystem increases, the number of control points, that the platform provider can monetize, increases as well. This may be a consequence of the value of the network relationships, which increase with the number of stakeholders in the ecosystem.

The wallet platform provider has multiple revenue streams - more than its sub-ecosystems - generated by its relationships with value-added service providers (e.g. licensing APIs), payment service providers (e.g. transaction fees), consumers (e.g. transaction fees and big data) and merchants (e.g. transaction fees and big data). What it is to be discussed yet, it is the extent to and on which control points banks should decide to collaborate and/or compete. In fact, it is quite evident that it is not rationale for any player to compete commercially across all the control points and a high degree of cooperation is needed among stakeholders to have a healthy ecosystem. Even if it is not the interest of this paper, it is useful outlining that "Banks will cooperate with fintechs and leverage their platforms as a new channel to reach customers and over 90\% of banks see it as necessary" says the consulting firm Edgar, Dunn \& Company. Banks realize that these firms are differentiating themselves by offering innovative products and services, and enhancing customer experience. Thus, Fintechs and other actors in the ecosystem should be no longer viewed by banks as competitors only, but as potential partners (Bose \& Denis, 2017). 
In order to optimize their decision-making processes regarding strategic positioning and business models in the new payment landscape, first, banks need to figure out which are their core competences - their strengths - and, instead, which weaknesses they have in comparison with Fintechs and other new-comers in the mobile wallet market.

Banks and Fintechs have indeed complementary strengths and weaknesses. For both parties, a partnership could create synergies, so that they could focus on their core competencies and contribute with these areas of expertise to the innovation process. Taking a bank perspective:

- Banks can bring well-established infrastructure, alongside with specific financial knowledge - risk assessment and management, compliance, local regulatory specifics and treasury needs (Deutsche Bank AG, 2016).

- Banks have deep customer knowledge and the experience and credibility to run the Know Your Customer (KYC) process that is required when a payment instrument comes out.

- Banks can count on a huge pre-existing customer base needed to get the adoption process faster and smoother (Deutsche Bank AG, 2016; Ferrari, 2016).

- Consumers' trust is a central component for achieving mass adoption of mobile wallet solutions. Banks are by far consumers preferred and most trustworthy mobile wallet provider (First Annapolis, 2017; Statista.com, 2017). Being secure is a primary consumers' concern that prevented mobile payments to widespread in the past, these data provide a solid ground for banks on which they can develop a winning strategy.

- Banks are already part of a network economy, making them widely accepted worldwide and allowing them to provide their own payment instruments and other services (Omarini, 2015).

On the Fintech side:

- Fintech comapnies can rely upon an agile structure and technological expertise regarding the digitalization process, including big data collection and usage, artificial intelligence and web and smart-device technology (Bose \& Denis, 2017).

- Fintechs are not characterized by internal siloes and legacy systems, so that they can provide a bridge between banks and the end markets (Tabakovic \& Sylvest Olsen, 013).

- Fintechs have usually a more effective go-to-market strategy than banks, which have been traditionally more focused on products delivery rather than on customer-centric approaches (PwC, 2016).

In the market, there are few banks that can have deployed the resources and expertise to commercialize across the whole m-wallet ecosystems and value chains. For this reason, co-opetition model fits well the needs of banks and other stakeholders. At this point, before they come out with their $\mathrm{m}$-wallet offering and value proposition, financial institutions should first understand which are the critical control points' in the ecosystem useful to succeed and build sustainable competitive advantages.

The mobile wallet is an interesting example of banking moving toward a service-centered logic, based on a new view of retail banking organization and approach to market and business operations (Flatraaker, 2013). This new logic is grounded in the understanding of the role of connections between stakeholders, specializing in, and exchanging their core competences, within a business ecosystem, delivering value to it (Omarini, 2015; Tewari, 2014). The banking account relationship with clients should be a central element of this strategic shift, with banks connecting producers of products and services to the appropriate consumers of such products and services. Producers would include Fintechs, other third-party VAS providers, other banks, and other non-bank wallet platform providers. As discussed earlier, banks can leverage their broad understanding of customers' needs and payments expertise to play a leadership role, facilitating the exchange of valuable interactions between external producers and consumers (Sharma, Gusain, \& Kumar, 2013).

\subsection{Main Strategic Approaches for Retail Banks in the Mobile Wallet Ecosystem}

In light of the control points' analysis, there are four main strategic options, which are going to be pointed out in terms of mobile wallet service proposition banks could take into consideration. Benefits and drawbacks of each option will be analyzed as well. Figure 3 maps these different strategic options. 


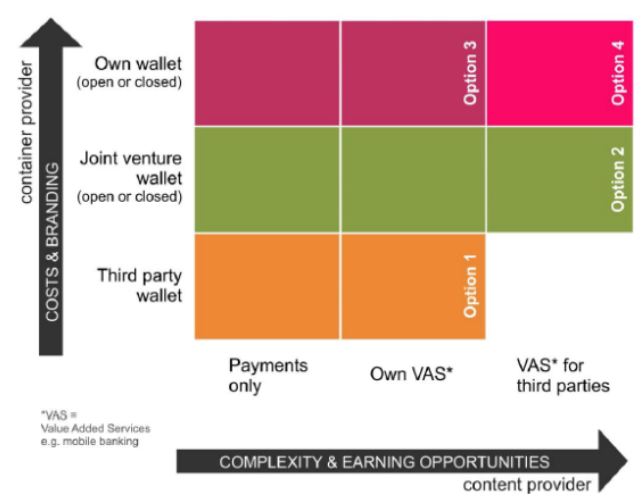

Figure 3. Mobile wallet: strategic options for banks

https://www.mobeyforum.org/wp-content/uploads/Mobile-Wallet-Part-5-Webinar.pdf

Tabakovic \& Sylvest Olsen, Mobile Wallet: Strategic Options for Banks, 2013

The four options presented are the result of a strategic mix in terms of range of services offered (content) and wallet ownership (container).

According to the breadth of services offered (horizontal axis), there are the following options for banks:

- $\quad$ Payment only services.

- Own value-added services in addition to payment services.

- Third-party value-added services in addition to own VAS and payment services.

It is quite expectable that the overall value of a mobile wallet solution is correlated positively with the breadth of services offered to the user to the extent to which the bank is able to select valuable and attractive additional non-payments services for users. Thus, the earnings opportunities as well as the complexity of the wallet solution increase in accordance with the breadth of services offered.

The vertical axis maps the different strategies as far as wallet ownership is concerned. Going through the ownership model, there are the following options:

- Service provider in third-party mobile wallet solution.

- Joint venture wallet developed with other partners.

- Fully owned wallet.

Clearly, moving up the ownership ladder entails a potential increase in brand value opportunities with all the benefits related in terms of customer loyalty, and others, but there are also significant costs (e.g. development, marketing), which may rise.

From the intersection of the aforementioned axes, four main strategic options for banks can be highlighted as we have summarized in Table 2, where benefits and drawbacks are outlined, as done in Tabakovic (2012), Henningsson \& Hedman (2015) and other several industry reports. In addition, Table 2 reports some considerations on the suitability of each option in relation with the bank's strategy and resources. 
Table 2. A framework of market entry options: pros, cons and suitable strategies for banks

\begin{tabular}{|c|c|c|c|}
\hline & Pros & Cons & Suitable Strategy \\
\hline $\begin{array}{l}\text { Option 1: } \\
\text { Third-party } \\
\text { mobile wallet }\end{array}$ & $\begin{array}{l}\text { - Limited efforts on resource perspective } \\
\text { (e.g. no development costs) } \\
\text { - Economies of scope: the bank leverages on } \\
\text { resources already in place (e.g. payment } \\
\text { channels) } \\
\text { - Speed to market } \\
\text { - Rich ecosystem with potential benefits such as } \\
\text { external knowledge spillovers }\end{array}$ & $\begin{array}{l}\text { - Lack of decision power } \\
\text { within the wallet } \\
\text { ecosystem } \\
\text { - Low brand visibility } \\
\text { - No direct relationship with users } \\
\text { - Little possibility for } \\
\text { differentiation }\end{array}$ & $\begin{array}{l}\text { - Banks not willing to invest high } \\
\text { level of resources } \\
\text { - Banks partnering with TPPs with } \\
\text { strong brand value and customer base } \\
\text { (e.g. high-tech firms) }\end{array}$ \\
\hline $\begin{array}{l}\text { Option 2: } \\
\text { Joint venture } \\
\text { mobile wallet }\end{array}$ & $\begin{array}{l}\text {-Potential synergies creation with partners } \\
\text { (e.g. cost-savings, availability of } \\
\text { different core competences) } \\
\text {-Speed to market }\end{array}$ & $\begin{array}{l}\text {-Complex set up and } \\
\text { management of joint } \\
\text { venture solutions } \\
\text {-Low brand visibility }\end{array}$ & $\begin{array}{l}\text {-Banks able to find and partner } \\
\text { up with non-competing } \\
\text { entity } \\
\text {-Banks willing to be first movers in } \\
\text { the market }\end{array}$ \\
\hline $\begin{array}{l}\text { Option 3: } \\
\text { Proprietary } \\
\text { vertical mobile } \\
\text { wallet }\end{array}$ & $\begin{array}{l}\text {-Full control over technology, branding and } \\
\quad \text { market penetration strategy } \\
\text {-Cross-selling opportunities } \\
\text {-Data flow control and ownership as revenue } \\
\text { stream and tool to gain valuable customer's } \\
\text { knowledge } \\
\text {-Direct customers relationships and retention } \\
\text {-Opportunity for differentiation } \\
\text {-Brand visibility } \\
\text {-Other advantages from platform ownership: } \\
\text { network effects, scale advantage (Henningsson } \\
\text { \& Hedman, 2015) }\end{array}$ & $\begin{array}{l}\text {-Creation of attractive and } \\
\text { engaging content, } \\
\text { especially VAS may be } \\
\text { challenging } \\
\text {-Time and resource (e.g. high } \\
\text { development costs) consuming } \\
\text {-Agile organizational structure in } \\
\text { place required, generally lacking } \\
\text { in traditional financial institutions }\end{array}$ & $\begin{array}{l}\text {-Banks with an already brand } \\
\text { awareness and customer } \\
\text { base } \\
\text {-Banks with a broad offering of } \\
\text { services as well as capabilities to } \\
\text { differentiate services } \\
\text {-Banks with agile organizational } \\
\text { structure }\end{array}$ \\
\hline $\begin{array}{l}\text { Option 4: } \\
\text { Proprietary } \\
\text { horizontal } \\
\text { mobile wallet }\end{array}$ & $\begin{array}{l}\text {-Full control over technology, brand and } \\
\text { market penetration strategy } \\
\text {-Highest revenue potential: new revenues from } \\
\text { TTPs sharing their profits in exchange for the use } \\
\text { of the platform; data flow control and ownership } \\
\text { as revenue streams, and tools to gain valuable } \\
\text { customer's knowledge } \\
\text {-Rich ecosystem with wide range of VAS, while } \\
\text { maintaining platform ownership and potential } \\
\text { external knowledge spillovers } \\
\text { - Direct customers relationships and retention } \\
\text { - Opportunities for differentiation } \\
\text {-Other advantages from platform ownership: } \\
\text { network effects, scale advantage }\end{array}$ & $\begin{array}{l}\begin{array}{l}\text {-Time and resource (e.g. high } \\
\text { development costs) } \\
\text { consuming }\end{array} \\
\text {-Operational complexity, } \\
\text { involving negotiations with other } \\
\text { service providers } \\
\text {-Risk of brand dilution }\end{array}$ & $\begin{array}{l}\text {-Banks pursuing strong } \\
\text { digitalization strategy, } \\
\text { aiming to be market leaders } \\
\text { in the area - shapers of the } \\
\text { industry } \\
\text {-Banks willing to invest high amount } \\
\text { of resources - money and time - to } \\
\text { build a rich ecosystem, developing } \\
\text { services as well as managing } \\
\text { partnerships }\end{array}$ \\
\hline
\end{tabular}

\subsection{A set of Business Cases}

In the previous paragraphe, we focused on how financial institutions can set up their entry strategies and their business models in the m-wallet market. We are now going to move a bit further on the analysis of some specific case studies related to the development and launch of mobile wallet platforms in which financial institutions adopted 
different strategies and took on different roles. We have pointed out that multiple roads can be undertaken for banks. The cases selected regard some of the different strategic options, we described, so to understand better the rationale main benefits the banks aim to achieve across the different value dimensions - and the strategy adopted, and in doing so, we are following the framework developed by Sang Un Chae \& Hedman (2015). In Table 3 we summarize the four selected examples.

Table 3. Business cases in the mobile wallet ecosystems

\begin{tabular}{lll}
\hline \multicolumn{1}{c}{ Stratecig options: } & Bank and the Type of wallet & \multicolumn{1}{c}{ Other examples } \\
\hline Proprietary horizontal mobile wallet & Chase Pay & BBVA Wallet \\
& (JPMorgan Chase - US) & $\begin{array}{l}\text { Citi Pay (Citibank) } \\
\text { Wells Fargo Mobile Wallet }\end{array}$ \\
\hline Joint venture mobile wallet & Swish & Zelle (30 US Banks) \\
(six Nordic Banks - Sweden) & $\begin{array}{l}\text { Commonwealth Bank of Australia, National } \\
\text { Australia Bank and Westpac (October 2017) } \\
\text { revealed they would back Beem It }\end{array}$ \\
\hline Third party provider mobile wallet & Alipay Wallet & Orange Cash (Orange and Visa Europe) \\
\hline
\end{tabular}

The first example is that of Chase Pay as proprietary wallet, in which Chase controls the end-user interface, a key initiation network hub. However, Chase offers also its payment services in third party provider wallets. The main rationale behind this choice is explained by Gordon Smith, Chief Executive Officer of Chase Consumer \& Community Banking.

"Our strategy has been consistent: Build our own proprietary wallet with Chase Pay; Be top of wallet in other wallets, whether that is Apple Pay, Android Pay, Samsung Pay, or other embedded payment systems such as Amazon or Uber."

The bank believes in the value for customers of a rich variety of services, in order to allow the bank "to offer $a$ Chase solution anywhere a customer might go" says Dina DeMerell, Chief Marketing Officer at Chase Pay.

In the same time, the Bank has adopted a mixed strategy, developing its own proprietary wallet but being top of wallet into TPPs' wallets, to achieve two sets of goals. On the one hand, Chase aims to consolidate its leading position as m-wallet provider among banks. On the other hand, the Bank is keen to solve the chicken-egg problem on the adoption. In fact, by including its wallet into other players' wallet, Chase sees the chance to boost the adoption of its services on the consumer's side. In particular, Dina DeMerell, Chief Marketing Officer at Chase Pay said:

"We're supporting those products actively, we want customers to select Chase as their payment method for apple or Samsung pay. If that's the product the customer wants to use, we want to make it easy for them to connect with Chase."

Chase can also leverage on a lower level of transaction fees to become the favorite payment option for users. In conclusion, a mixed strategy may be effective if a bank is able to comptete to become top of wallet into other wallets and, to do so, the bank needs to have competitive advantage in terms of value proposition to consumers and/or to merchants (e.g. low transaction fees).

Chase is trying to maximize adoption of the service, cooperating with third-party providers through the availability of Chase Pay services in their app, while competiting through the offering of its own proprietary wallet. Chase is playing the role of keystone in the wallet ecosystem and not only in the Chase Pay ecosystem. Offering its payment services (e.g. Chase's Freedom card) into other wallets, it is indeed sustaining the adoption of wallet solutions and the overall growth of the whole market as well as increasing top-of-wallet status for its payment cards and growing the percentage of spending that consumers do on Chase cards versus competitors. Chase recognizes the high value of value-added services into the mobile wallet, and is aiming to build a wide network of merchants, accepting Chase 
Pay as payment methods as well as providing additional services. Chase is also collaborating with Fintechs to build technological infrastructure, especially via merger and acquisitions, such as the acquisitions of MCX and WePay, trough which Chase provides a significant example of the complementarity between banks and Fintech.

It is too early to realize which entity or business model will win the wallet battlefield, as the market is developing every day. Moreover, it can be said that the sub-ecosystem represented by cashless (mainly card) payment influenced the broader wallet ecosystem in terms of stakeholders' acceptance and use of cashless solutions. Offering a broader range of banking products and services is an important issue to pursue, anyway. Cross selling is indeed a key aspect to leverage for any wallet providers. The second case is that of the joint venture developed by six Nordic banks (Danske Bank, Handelsbanken, ICA Banken, Länsförsäkringar, Nordea, SEB, Skandia, Sparbanken Syd, Swedbank \& Sparbankerna, Ålandsbanken), in collaboration with the government and the central bank, troughout Bankgirot, a clearing system platform owned by those banks. Swish value proposition evolved since its launch. Peer-to-Peer payment was the original service provided by the consortium app. Business-to-Business payments solution was introduced in 2014. Consumer-to-Business online payment function was added in a further stage in 2016 and eventually proximity payments using QR code technology. Overall, the value proposition of Swish for users and merchants is run on the simplicity of the extremely user-friendly mobile app. The strategy of the joint venture to start with P2P payments and then move to other forms of mobile payments is related to the lower degree of complexity of $\mathrm{P} 2 \mathrm{P}$, being instant transfers directly from users' bank accounts. The main strength in this project is also the leadiong roles of some important stakeholders such as the central bank and the government. All this allowed the consortium to launch the product faster than competitors, a key objective as Gunnar Ölundh, Vice President and Director of Infrastructure at Bankgirot, explained it as follows:

Given the competitive pressure, our member banks realized that they would have to be more aggressive in time-tomarket for their mobile phone payments service, as well as the extent to which they marketed it before the launch.

Moreover, P2P are easier to be accepted by users because they exchange small amounts of money. Only when the app started gaining a solid customer base trusting the service, Swish added new B2B and C2C functionalities. This project has leveraged on its time-to-market as a source of value creation in the mobile payments industry and on the JV-based m-wallet, which accelerated the development and launch of the wallet. In addition, a bank-owned joint venture wallet scores very high in consumers' acceptance and trust, facilitating new technology adoption.

The third case is that of the participation in Third Party Provider (TPP) wallet (Guo \& Bouwman, 2016), named Alipay Wallet from Alibaba Group. Alipay Wallet has been developed by the Fintech Alipay, that is currently the most popular wallet platform in the world, thanks to its large diffusion in the Chinese market. It is a mobile wallet platform, fully onwed by Ant Financial Service Group, a subsidiary of the Chinese group Alibaba Group. There are interesting factors to outline, such as the fact that banks joining Alipay do not need to deploy other resources than their core ones they already have in place (e.g. banking systems and licenses), so that they can leverage economies of scope. Alipay has over 700 million users that banks, joining the wallet, can target with their banking services. There is also an interesting time-to-market advantage so that banks do not need to spend time on developing their own wallet if they join Alipay. Alipay is a very rich ecosystem, including massive participation of merchants and other stakeholders. Being part of it can help banks build solid network and gain benefits from external knowledge spillovers.

To conclude, it can be outlined that developing a proprietary horizontal wallet, as we have seen for Chase Pay, has the potential to generate more value creation than other solutions, especially compared to mere participation in third party wallet. However, the level of resources, both internal and external, required to pursue this approach are significantly higher as well. On the other hand, participation in third-party wallet requires to hold resources that all banks have already in place (e.g. payment channel infrastructure, licenses, etc.). We could then argue that banks' strategy on this matter should be driven by a careful assessment of the resources each one has inside and on the willingness and ability to deploy a mobile wallet business.

This analysis confirms the hypothesis that the broader the wallet value proposition, the higher potential of value creation for banks, under the conditions that a bank is able to deploy the appropriate resource level and that the context in which it operates is consistent with its strategy. In fact, a significant element affecting this assessement is the external environment, including market size, consumers' openness to innovation, regulation, and the competitive landscape.

\section{Conclusions and Managerial Implications}

Technological innovation, recent regulatory initiatives and mass consumers' changing expectations are quickly 
re-shaping the payments' sector, paving the way to a more open environment where even non-banking players see a huge opportunity to gain momentum and disrupt the incumbents (retail banks and other financial institutions). Fintechs startups, high-tech firms but also mobile network operators are indeed challenging the status quo with their innovative propositions, trying to disintermediate banks from their traditional function of payment service providers. In the payments market, mobile wallets represent one of the innovations with highest potential of growth in the consumer-to-business segment. Mobile wallets are digital platforms, through which a wide range of services, including both payment non-payment services are delivered to end users.

The case studies show the tendency for banks to combine the development and commercialization of a proprietary mobile wallet with the participation in third party wallet, especially device manufacturers (e.g. Apple Pay). This is likely a consequence of the large customer base of these players, as well as their interest in controlling the mobile hardware, which is a key network hub within the ecosystem. However, the level of resources, both internal and external, required to pursue this approach are significantly higher. Developing a proprietary horizontal wallet, as we have seen for Chase Pay, has the potential to generate more value creation than other solutions, especially compared to mere participation in third party wallet. On the other hand, participation in third-party wallet requires only resources that all the banks have already in place (e.g. payment channel infrastructure, licenses, etc.).

This analysis confirms the hypothesis that the broader the wallet value proposition, the higher potential of value creation for banks, under the conditions that banks are able to deploy the appropriate resource level and that the context in which they operate is consistent with their strategy. As it is well known, banks have struggled with customer intimacy issues for many reasons. Mobile wallet can be an interesting tool to reinvent their bank-customer relationships, but banks have to manage the mobile paradigm efficiently, and not view it, as a merereplacement for the teller or as a complementary alternative for the entire branch, but as a way to develop new customer-engagement services.

Retail banks' positioning strategy on this matter should be driven by a careful assessment of the resources each bank holds as well as it is able and willing to deploy in the mobile wallet business. All the stakeholders in the mobile wallet ecosystem look for finding out the relevant control points in order to assess their relative position within the ecosystem and be able to exploit potential sources of competitive advantage. Striclty linked to this, there is the big issue to manage Big Data and being reactive to update or innovate their product lines.

\section{Acknowledgement}

The author would like to thank Riccardo Aghito - MsC of Finance - for his job in providing some references. The views expressed in the article are the authors' alone.

\section{References}

Arner, D., Barberis, J., \& Buckley, R. (2015). The evolution of fintech: a new post-crisis paradigm?

Au, Y. A., \& Kauffman, R. J. (2008). The Economics of Mobile Payments: Understanding Stakeholder Issues for an Emerging Financial Technology. Electronic Commerce Research and Applications, 7(2), 141-164. Retrieved from https://ink.library.smu.edu.sg/sis_research/2130

Ballon, P. (2007). Business modelling revisited: the configuration of control and value. The Journal of Policy, Regulation and Strategy for Telecommunications, Information and Media, 9(5), 6-19.

Blake M., \& Vanham, P. (2016, November 30). Five things you need to know about fintech. World Economic Forum. Retrieved from https://www.weforum.org/agenda/2016/04/5-things-you-need-to-know-about-fintech/

Bose, A., \& Denis, J.-F. (2017). World Payments Report 2017. Capgemini \& BNP Paribas.

Boudreau, K. J., \& Hagiu, A. (2008, September 18). Platform Rules: Multi-Sided Platforms as Regulators. Retrieved January 5, 2018, from https://ssrn.com/abstract=1269966

Broom, D. (2015). Innovation in Payments: The Future is Fintech. New York City: BNY Mellon.

Chishti, S., \& Barberis, J. (2016a). The Book of Fintech. Wiley. https://doi.org/10.1002/9781119218906

Chishti, S., \& Barberis, J. (2016b). The Tech Book (1st ed.). New Dehli: Wiley.

Dahlberg, T., Guo, J., \& Ondrus, J. (2015). A critical review of mobile payment research. Electronic Commerce Research and Applications, 14, 265-284. https://doi.org/10.1016/j.elerap.2015.07.006

de Reuver, M. V. (2015). Collective action for mobile payment platforms: A case study on collaboration issues between banks and telecom operators. Electronic Commerce Research and Applications, 14(5), 331-344. https://doi.org/10.1016/j.elerap.2014.08.004 
Debray, A., Kwon, H., \& Gill, R. (2014). Mobile Money Opportunities for Mobile Operators. Mobey Forum.

Deloitte. (2015). Swiss Banking Business Models of the Future. Embarking to New Orizons, Report.

Deutsche Bank AG. (2016). FinTech 2.0: Creating new opportunities through strategic alliance. Frankfurt: Deutsche Bank.

Drummer, D., Jerenz, A., Siebelt, P., \& Thaten, M. (2016). FinTech - Challenges and Opportunities. McKinsey \& Company.

Edgar, Dunn \& Company. (2017). Advanced Payments Report 2017. Wirecard.

Eisenmann, T., Parker, G., \& van Alstyne, M. (2006). Strategies for two-sided markets. Harvard Business Review, 84(10), 92-101.

European Payments Council. (2018). SEPA payment scheme management. Retrieved January 22, 2018, from https://www.europeanpaymentscouncil.eu/what-we-do/sepa-payment-scheme-management

Faber, E., Ballon, P., \& Bouwman, H. (2003). 'Designing business models for mobile ICT services. Positioning paper for Workshop on Concepts, Metrics and Visualisation, Bled Ecommerce Conference in Bled at 9-11 June.

Ferrari, R. (2016). L'Era del Fintech. Milano: Franco Angeli.

Flatraaker, D.-I. (2013). Mobile payments changing the landscape of retail banking: Hype or reality? Journal of Payments Strategy \& Systems, 7(2), 150.

FSI, F. S. (2017, June 27). Financial Stability Implications from FinTech, Supervisory and Regulatory Issues that Merit Authorities' Attention.

Grassie, K. (2007). Easy handling and security make NFC a success. Card Technology Today, 19(10), 12-13. https://doi.org/10.1016/S0965-2590(08)70134-8

Guaus, J. (2013). Structures and Approaches: The Changing Face of the Mobile Wallet. Mobey Forum.

Guo, J., \& Bouwman, H. (2016). An ecosystem view on third party mobile payment providers: a case study of Alipay. International Journal of Retail and Distribution Management, 56-78.

Henningsson, S., \& Hedman, J. (2015). The New Normal: Market Cooperation in the Mobile Payments Ecosystem. Electronic Commerce Research and Applications, 15(15), 305-318.

Hoffman, K. E. (2017). The mobile wallet challenge. Independent Banker, 4, 73-75.

Iansiti, M., \& Levien, R. (2004). The Keystone Advantage: What the New Dynamics of Business Ecosystems Mean for Strategy, Innovation, and Sustainability. Boston: Harvard Business School Press.

ISO20022.org. (2018). Full catalogue of ISO 20022 messages. Retrieved January 23, 2018, from https://www.iso20022.org/full_catalogue.page

JP Morgan. (2015). Chase Announces CHASE PAY. Retrieved January 15, 2018, from https://www.jpmorganchase.com/corporate/investor-relations/pr/chasepay-announced.htm

Karvonen, J., \& Warsta, J. (2004). Mobile multimedia services development: value chain perspective. Paper presented at the Proceedings of the 3rd international conference on Mobile and ubiquitous multimedia MUM '04. https://doi.org/10.1145/1052380.1052404

Kazan, E., \& Damsgaard, J. (2013). A Framework For Analyzing Digital Payment As A Multi-Sided Platform: A Study Of Three European NFC Solutions. Retrieved January 2, 2018, from http://aisel.aisnet.org/ecis2013_cr/133

Kotarba, M. (2016). New Factors Inducing Changes in the Retail Banking Customer Relationship Management (CRM) and Their Exploration by the Fintech Industry. Foundations of Management, 8.

KPMG. (2016). The profitability of EU banks. Retrieved Decemebr 15, 2017, from https://assets.kpmg.com/content/dam/kpmg/xx/pdf/2016/10/the-profitability-of-eu-banks.pdf

Ley, S., Foottit, I., \& Honig, H. (2015). Payments disrupted - The emerging challenge for European retail banks.

Linder, J., \& Cantrell, S. (2000). Changing Business Models: Surveying the Landscape. Institute for Strategic Change, Accenture.

Lindmark, S., Bohlin, E., \& Andersson, E. (2004). Japan's mobile internet success story - facts, myths, lessons and implications. Info, 6(6), 348-358. https://doi.org/10.1108/14636690410568623 
Liu, P., \& Yi, S.-P. (2016). The Effects of Extend Compatibility and Use Context on NFC Mobile Payment Adoption Intention. In I. L. Nunes (Ed.), Advances in Human Factors and System Interactions.

McKinsey \& Company. (2015). Global_payments_2015_A_healthy_industry_confronts_disruption.pdf, personalized and interactive experiences, contributing to increased conversion rates. McKinsey \& Company.

McKinsey \& Company. (2017). Global Payments 2017: Amid Rapid Change, An Upward Trajectory.

Methlie, L.B., \& Pedersen, P.E. (2002). A taxonomy of intermediary integration strategies in online markets, paper presented at the 15th Bled Electronic Commerce Conference in Bled at June 17-19.

Moore, J. (1996). The death of competition: leaderships and strategy in the era of ecosystems. New York: NY-Harper Collins.

Murad, A. (2015, October 14). Start-ups aim at banks' income streams. Retrieved November 2, 2017, from https://www.ft.com/content/55049480-61cb-11e5-9846-de406ccb37f2

Nicoletti, B. (2014). Mobile Banking - Evolution or Revolution?. Palgrave Macmillan.

Nicoletti, B. (2017). The Future of FinTech (1st ed.). Rome: Palgrave Macmillan.

Omarini, A. (2015). Retail Banking - Business Transformation and Competitive Strategies for the Future (1st ed.). Palgrave McMillan.

Parker, P. (2014). Mobile Wallet Definition. Retrieved November 10, 2017, from https://www.cardpaymentoptions.com/glossary/mobile-wallet-definition/

Pham, T.-T., \& Ho, J. (2015). The effects of product-related, personal-related factors and attractiveness of alternatives on consumer adoption of NFC-based mobile payments. Technology in Society, 43, 159-172. https://doi.org/10.1016/j.techsoc.2015.05.004

PwC. (2016). Global FinTech Report. PwC.

PwC. (2016). What is Fintech? Retrieved June 2018, from https://www.pwc.com/us/en/financial-services/publications/viewpoints/assets/pwc-fsi-what-is-fintech.pdf

Sang Un Chae, J., \& Hedman, J. (2015). Business Models for NFC based mobile payments. Journal of Business Models, 3(1), 29-48.

Sareen, P., \& Tewari, A. (2014). Platform Business Models and Mobile Ecosystems.

Shapiro, C., \& Varian, H. R. (1999). Information rules: A strategic guide to the network economy. Harvard Business Review.

Sharma, V., Gusain, P., \& Kumar, P. (2013). Near Field Communication. TULA's Institute, The Engineering and Management College: Atlantis Press.

Statista.com. (2016). Number of smartphone users worldwide from 2014 to 2020 (in billions). Retrieved from https://0-www-statista-com.lib.unibocconi.it/statistics/330695/number-of-smartphone-users-worldwide/

Statista.com. (2017). FinTech Report - December 2017.

Staykova, K., \& Damsgaard, J. (2015). The race to dominate the mobile payments platform: Entry and expansion strategies. Electronic Commerce Research and Applications, (14), 319-330. https://doi.org/10.1016/j.elerap.2015.03.004

Tabakovic, A. (2012). Control Points in Mobile Wallets. Mobey Forum - Tim Haines.

Tabakovic, A., \& Sylvest Olsen, K. (2013). Mobile Wallet: Strategic Options for Banks. Mobey Forum.

Tavilla, E. (2017). Rewarding Loyal Customers to Increase Mobile Payments Adoption. Boston: Federal Reserve Bank of Boston.

Téllez, J., \& Sherali, Z. (2017). Mobile Payment Systems. Swindon, UK: Springer International Publishing AG.

Tewari, A. (2014). Platform Business Models and Mobile Ecosystems. ResearchGate.

Turowski, K., \& Pousttchi, K. (2013). Mobile Commerce. Springer-Verlag.

Verona, G. (2015). Network Externalities - Lecture Notes. Milano: Università Commerciale Luigi Bocconi.

Waupsh, J. (2017). Bankruption - How Community Banking Can Survive Fintech (1st ed.). Hoboken: Wiley. 